bringing water, but its position in Teneriffe during summer is favourable for making it deposit any which may be present."

I think from these extracts, which are supported by other passages in Prof. Smy li's work, I am quite justified in arguing that the trades and couster-trades are not similar in their constituents, that their degrees of electricity and of saturation are not the same, and that therefore it is not reasonable to suppose that their upper currents intermingle at the belts of tropical calms, and that their mixed volume descends and is then drawn off north and south as required, to restore the equilibrium of the atmosphere.

As these opposite currents flowing in the northern hemisphere from the north-east and the south-west (approximately) do not intermingle, and their mixed volume does not descend in the calms of Cancer it must necessarily follow that the south-west or return equatorial current, does descend to the surface of the ocean on the polar side of the calms of Cancer, and equally that the north-east upper current does descend on the equatorial side.

I lave by no means exhausted what I have to say on this subject, but Mr. Ley will doubtless understand that I am unable to treat it at greater length in your columns. The same line of argument would have enabled me to answer Mr. Ley's questions separately had space permitted. DIGBY MURRAY

\section{Mind and Matter}

Permit me to correct a mistake on the part of Mr. Tupper (NATURE, vol. xv. p. 217), who, though starting with a correct notion that my letter (NATURE, vol. xv. p. 78) was intended to solve a problem, immediately fell into the error of regarding it as intended to prove an alleged fact.

The fact alleged, that consciousness depends on nervous organisation $I$ assumed to be a fact, and undertook to indicate how the dependence might be conceived, or regarded, to exist.

First, I alleged that the hypothesis of matter being as susceptible of consciousness as spirit, was quite conceivable, as a hiypothesis, whether or not it should be proved afterwards to be a wrong hypothesis.

Second, the connection of two so dissimilar entities as matter and subjectivity had not the objection of being anomalous or uniciuc; for energy and matter were equally dissimilar and yet invariably united. The parity of mystery was not intended to establish "parity of probability as to the facts," but merely parily of conceivabizity. For it is surely some help to our entertaining a new conception if we can point to an existing similar conception.

Third, if such a mysterious entity as energy conld be divided and combined (using the words in a loose serise) why should there be a difficulty in conceiving of the division and combination of subjectivity. By this I meant that as division of matter involved division of energy, as to amount, so division of matter might be conceived involving division of subjectivity, as to amount: so with combination.

Thus far, however, I had only cleared away difficulies "real or apparent" in the way of our conceiving the relation of consciousness to matter from the " materialistic" stand-point.

The essential part of my solution which indicated roughly the modus of the connection between matter and consciousness and which dealt with the great difficulty of the question-How to account for the two aspects of matter, the unconscious and conscious? - has not been touched hy Mr. Tupper. This portion he excused himself from examining because he regarded it as bascd on the assumption that "the probability of subjectivity being a property of matter equals the fact of energy being related to matter," whereas it is based on the fact, or alleged fact, or assumption, that "the dependence of consciousness on nervous organisation seemed by the science of nerve-physiology to be fairly established." To mistake allegations of the conceivability of a notion for assumptions or intended proofs that the notion is true, as has been done by Mr. Tupper, is strely not equivalent to pointing out fallacies in the solution of a problem.

Will he admit that, if a "pointer" could " tell us" he scented a fox and immediately thereafter follow the scent of a hare such would be an admirable analogy of how to practise "sound logic by the old à priori method?"

Stafford, January I 7

W. S. DUNCAN

\section{Pre-Glacial Man in America}

DR. AвВотT, in his interesting letter on the traces of preglacial man in America, supposes that it may be correct that the
American aborigines migrated from the Old World. This may be the case with the Red Indians, but we know that they drove out an earlier people--the mound-builders. However, both mound-builders and Red Indians were certainly post-glacial in their occupation of the northern parts of America, and the oldest traces of their existence may not date back to an earlier time than a late stage of the Neolithic period in Europe.

Palreolithic man in America holds the same relative position to these later peoples as he does in the Old World, and we have so far obtained no evidence to show whether he occupied Europe or America first. The position of his remains in the auriferous drift of California is the same as in that of Siberia; in the löess of the Mississippi as in that of the Danube and the Rhine; in the caves of Brazil along with extinct mammalia as in those of Europe; and in the lowland gravels of Virginia as in those of France and England.

The question of the post or pre-glacial age of palæolithic man depends in America as it does in Europe on that of the age of the deposits in which they are found, and this is at present a matter of inquiry and discussion which might be set at rest, as I have pointed out in the Quarterly Fournal of Science for July of last year, by a thorough examination of the brick clays at Hoxre where paleolithic implements were first found in England.

Cornwall House, Ealing, January 27 Thomas BeLT

\section{Holly Berries}

REPORTS of the scarcity and abundance of holly berries have appeared in NATURE from the south-east of England and west of Scotland respectively. It may be interesting to note the con. dition of the holly crop at a point somewhere about midway between these two places. In North Staffordshire and Derbyshire the holly berries are by no means scarce. They are not so plentiful as they were last year, but there is a fair average crop.

I have seldom seen such crops of them as I saw in several places in South Wales about a month ago. It may be also worth adding that the most teeming bush $\mathrm{I}$ saw was at a place in Cardiganshire, which was as far as I could learn--and I made diligent-inquiries---between four and five miles from the neares: hive of bees. I questioned closely several children on the $s_{5}$ :o: who were intelligent enough to give me a minute descripti on of most of the common birds and insects; not one of them had ever seen a bee.

Denstone College, Staffordshire

D. EDWARDes

\section{The Meteor of January 7}

AMONG the "Notes" in NATURE, vol. xv., p. 244, there is a description of a large meteor, of which $I$ was fortunate enough to secure a good observation; but on comparing the appdeni path, as observed by myself, with that recorded in the para: raph, I find the latter somewhat imperfect; the apparent path, as seen from near London, seems to have been curtailed both at beginning and at end of flight; probably the observer in question could further amplify his remarks, or some other correspondent send an observation. The following is an abstract from my note-book :-

"Birmingham, January 7, I0'3I P.M. G.M.T.--Meteor pear. shape, deep yellow merging into ruby-red towards the tail ; commenced as a luminous point near $\eta$ Hydræe, gradually increased in size, motion very slow and unsteady, appeared to force its way with difficulty, and slight undulation. Near $\alpha$ Leonis it attained the apparent size of Venus, the forward hemisphere now showing signs of internal commotion by the projection of ebullition prominences, which were swept back towards the tail, then $8^{\circ}$ long, and vaporous. The latter portion of its flight was intercepted by houses, but on emergence it burst with a flash below $\beta$ Leonis at A.R. $182^{\circ}$, D.N. $16^{\circ}$. Length of path, $52^{\circ}$; time of flight, five to six seconds ; radiant point (in Fluvius Eridanus), No. 96 Tupman, or No. $\times 64$ of the B. A. Catalogue.

Balsall Heath Road, Moseley Road, Birmingham

\section{Spectrum of New Star}

THE spectrum of the new star in Cygnus is changeable, and is now very unlike Cornu's representation of it in a recent number of NATURE (vol. xv., p. ${ }^{58}$ ). Your readers may not be aware that it is easy to see several of the bright lines without a powerful instrument, though not to measure them accurately. As "observed with a Browning's "miniature spectroscope" attached to a $44_{4}^{1}$-inch refractor, the brightest line is now about at 